The Economic Joumah 108 (January), 26-43. (C) Royal Economic Society 1998. Published by Blackwell Publishers, 108 Cowley Road, Oxford OX4 1JF, UK and 350 Main Street, Malden, MA 02148, USA.

\title{
EXPLAINING INTERNATIONAL AND INTERTEMPORAL VARIATIONS IN INCOME INEQUALITY*
}

\author{
Hongyi Li, Lyn Squire and Heng-fu Zou
}

\begin{abstract}
This paper explores the propositions that, income inequality is relatively stable within countries; and that it varies significantly among countries. A new and expanded data set provides broad support for both propositions. Drawing on a political economy and capital market imperfection arguments to explain the intertemporal and international variation in inequality, the empirical analysis shows that the predicted variables associated with the first argument (a measure of civil liberties and the initial level of secondary schooling) and the second argument (a measure of financial depth and the initial distribution of land) are indeed important determinants of inequality.
\end{abstract}

This paper explores two propositions regarding income inequality. They are: first, income inequality is relatively stable within countries; and second, it varies significantly across countries. ${ }^{1}$ To illustrate, note that the Gini coefficient in India remained almost constant for forty years (1951-92) with mean 32.6 and standard deviation $2.0 .^{2}$ In contrast, the variation in Gini coefficients across countries is large: 61.9 in Honduras in 1968 compared with 17.8 in Bulgaria in 1976. If substantiated, these propositions have potentially significant implications for poverty. The significance of the first is obvious - barring any fundamental socio-political change, poverty reduction will depend crucially on the rate of economic growth. Given this, the significance of the second is that in inegalitarian economies the poor will enjoy a smaller share of any national increment in income than in more egalitarian ones.

Drawing on a new and expanded data set on inequality (Deininger and Squire, 1996a), the first of the paper's three sections conducts standard statistical tests of the two propositions. The sample comprises 573 observations on the most common measure of inequality - the Gini coefficient - for 49 developed and developing countries covering the period 1947-94. The results broadly confirm our two propositions. Specifically, analysis of variance (ANOVA) shows that about $90 \%$ of the total variance in the Gini coefficients

* The authors wish to thank Paul Armington, Francois Bourguignon, Klaus Deininger, Shanta Devarajan, Bill Easterly, Sebastian Edwards, Gary Fields, Emmanuel Jimenez, Ross Levine, Branko Milanovic, Vikram Nehru, Lant Pritchett, Martin Ravallion, Mary Shirley, Holger Wolf, Chi-wa Yuen and participants at a World Bank workshop for very helpful comments on an earlier version of this paper. We are very grateful to the two referees and Timothy Beasley (the editor) for their detailed suggestions, which led to a substantial revision of the paper. The findings, interpretations, and conclusions expressed in this paper are entirely those of the authors. They do not necessarily represent the views of the World Bank, its Executive Directors, or the countries they represent. The paper should not be cited without the authors' permission.

1 We also explore a weaker, combined version of these two propositions - namely, that intertemporal shifts in inequality are modest compared with international differences.

2 The mean Gini coefficient for India reported in Table 2 is 39.15 . This is after the data have been adjusted for difference in definitions. The mean for the unadjusted data is $\mathbf{3 2 . 5 5}$. 
can be explained by variation across countries, while only a small percentage of the total variance is due to variation over time. Similarly, regression analysis reveals significant differences across countries, and fails to detect any significant time trend in 32 countries. Moreover, in 10 of the 17 cases where the data reveal a significant trend, it is quantitatively small - an annual change of less than $1.0 \%$ of the country's average Gini coefficient. To take a typical example, Jamaica shows a statistically significant and negative time trend but the change in its Gini coefficient from its 1980 value of 49.9 would be only 0.2 points a year. At this rate, it would take Jamaica 70 years to bring its Gini index in line with the average index for all countries in our sample - 36.2. In this sense, the observed intertemporal changes are small relative to the observed differences across countries. On the other hand, seven of the countries in the sample have annual changes in excess of $1.0 \%$ indicating that in certain circumstances inequality as measured by the Gini index can change more quickly - in China the index was increasing during our sample period at a rate of $3 \%$ a year, the largest rate of change that we observed. What actually happened in these seven countries is an interesting issue for future research.

In general, our results suggest that inequality is determined by factors which differ substantially across countries but tend to be relatively stable within countries. The second section of the paper explores some possible determinants of inequality. To do so, it draws on two ideas that have recently received attention in the literature on inequality and growth. The first posits a link from income or wealth inequality to policy via a political economy argument. In its simplest form, the rich are assumed to have the resources to lobby for policies which are beneficial to them but may be harmful to the rest of the economy and to growth (see Bertola, 1993). The second idea has to do with imperfections in the market for credit. By preventing the poor from making productive investments (such as education), credit constraints arising from asymmetric information perpetuate a low and inequitable growth process (see, for example, Banerjee and Newman, 1991). Taken together, the two ideas suggest that an initial state of inequality may be expected to continue because the rich have the capacity to protect their wealth while the poor are unable to augment theirs.

We find considerable support for both these ideas. In particular, the key variables associated with the political economy argument (a measure of political freedom and initial secondary schooling) and those associated with the capital market imperfection (the initial degree of inequality in the distribution of assets as measured by the distribution of land and a measure of financial market development) are all shown to be significant determinants of current inequality. This suggests that the rich are indeed able to exercise sufficient control over economic policy at least to maintain their wealth while the nonrich encounter capital market imperfections that limit their capacity to accumulate capital, again reinforcing the tendency for unequal distributions of income to remain so. To check the robustness of our main findings, we conduct sensitivity analysis by controlling for various other factors identified in both theoretical and empirical work on inequality and growth. The results

(C) Royal Economic Society 1998 
suggest that our findings are quite robust. Section 3 concludes by linking our results to previous work on the relationship between growth and inequality.

\section{Testing the Two Propositions}

This paper uses a new data set on Gini coefficients. ${ }^{3}$ Starting with a total of 2,480 observations on Gini coefficients covering 112 developed and developing countries for the years 1947-94, several criteria were used to 'cleanse' the data. First, all observations had to be from national household surveys for expenditure or income; second, the coverage had to be representative of the national population; and third, all sources of income and uses of expenditure had to be accounted for, including own-consumption. In addition, for the purpose of this paper, all observations had to be from countries with at least four observations covering a reasonable part of the 47 year period. These procedures resulted in a sample of 573 observations covering 49 countries. This is the data set used in this study. Before presenting the sample descriptive statistics, we note two points.

First, the definition of what is being measured by the Gini coefficient in our sample varies across countries. Inequality can be measured by gross income, net income, or expenditure and it can be per capita or per household. The distribution of our sample by definitional differences is shown in Table 1. Because variation in definition can undermine the international and intertemporal comparability of the data, we include controls for different definitions throughout Section 1. The results indicate that differences between coefficients defined on net and gross income and between household-based and individual-based coefficients are not significant. Differences between expenditure-based and income-based coefficients, however, are significant. In subsequent analysis, therefore, we have adjusted the data following the procedure recommended by Deininger and Squire (1996a). Specifically, we adjust for differences between income-based and expenditure-based coefficients by systematically increasing the latter by 6.6 points, this being the average difference observed by Deininger and Squire $(1996 a)$.

Table 1

Distribution of Gini Coefficients by Different Definitions

\begin{tabular}{|c|c|c|c|c|}
\hline \multirow[b]{2}{*}{ Unit of observation } & \multicolumn{2}{|c|}{ Income } & \multirow[b]{2}{*}{ Expenditure } & \multirow[b]{2}{*}{ Total } \\
\hline & Gross & Net & & \\
\hline $\begin{array}{l}\text { Household } \\
\text { Individual }\end{array}$ & $\begin{array}{l}240 \\
102\end{array}$ & $\begin{array}{l}73 \\
78\end{array}$ & $\begin{array}{l}19 \\
61\end{array}$ & $\begin{array}{l}332 \\
241\end{array}$ \\
\hline Total & 342 & 151 & 80 & 573 \\
\hline
\end{tabular}

${ }^{3}$ For further details see Deininger and Squire (1996a).

(C) Royal Economic Society 1998 
Second, the method used to calculate the Gini coefficients also varies across different sources. To minimise this problem we have recalculated the coeffcients using a standard technique for as many observations as possible. ${ }^{4}$

With these points in mind, basic descriptive statistics for the adjusted data are reported in Table 2 . Here we simply note that the overall sample mean is 36.2 and the standard deviation is 9.2 . The number of observations per country is as follows: 28 countries have between 4 and 9 observations; 14 countries have between 10 and 19 observations; and 7 countries have 20 or more. In general, the developed countries have longer series and better coverage than the developing ones. As a preliminary test of our two propositions, note that the standard deviation of the means of the 49 countries (9.3) is substantially greater than any of the standard deviations of the within-country Gini coefficients for each country (see Table 2 ).

We begin with an analysis of the variance components of the Gini coefficients using the raw data. Table 3 reports the ANOVA results. Allowing for the fact that we have an unbalanced data set, we find that for the entire sample (Data set 1 ), $91.8 \%$ of the variance is cross-country variance, while only $0.85 \%$ is over-time variance. A total of $0.4 \%$ is due to the differences in definitions. Based on the F-values, only the country variation and variation due to income/expenditure definition are significant. After adjusting for the income/ expenditure definition differences as described above (Data set 2), the ANOVA results show that the variance due to income/expenditure drops from $0.34 \%$ to $0.04 \%$ and is statistically no longer significant. This provides statistical evidence that the adjustment is necessary and useful.

Disaggregating the data (unadjusted) by income level according to the classification in the World Development Report, we obtain similar results. For high-income countries (Data set 3 ), the cross-country variance is $\mathbf{8 2 . 5 \%}$ and the over time variance is only $1.9 \%$. The corresponding figures for lower- and middle-income countries (Data set 4 ) are $93.1 \%$ and $1.4 \%$. In this case, the variation due to income/expenditure definition is significant since most of the differences in income/expenditure occurs in this group. But, with the adjusted data, remaining variations due to definition are small and insignificant. We also repeated the ANOVA exercise for three subsamples in which we progressively increased the consistency of definitions: a subsample containing Gini coefficients based only on income (493 observations); a subsample containing only income-based and household-based Gini coefficients (313 observations); and a subsample containing coefficients defined on gross income per household (239 observations). In each case, the results (not reported) indicate that about $90 \%$ of the variation can be explained by country variation, while variation over time is small (1.1 to $1.7 \%)$.

We now turn to a least squares dummy variable regression which allows us to study individual country specific effects and perform explicit hypothesis testing

4 The computational tool (POVCAL) we used for recalculating the Gini coefficients is discussed in detail in Datt (1992).

(C) Royal Economic Society 1998 
Table 2

Summary Statistics of Gini Coefficients (Adjusted for differences in definitions)

\begin{tabular}{|c|c|c|c|c|c|c|c|}
\hline Code & Nob & Mean & St. dev. & Max & Min & Max-min & Coverage \\
\hline AUS & 9 & 37.88 & 2.91 & 41.72 & 32.02 & 9.70 & $69 \sim 90$ \\
\hline BEL & 4 & 27.00 & 0.76 & 28.25 & 26.22 & 2.03 & $79 \sim 92$ \\
\hline BGD & 10 & 35.83 & 1.55 & 39.00 & 33.34 & 5.66 & $63 \sim 92$ \\
\hline BGR & 28 & 23.30 & 3.34 & 34.42 & 17.83 & 16.59 & $63 \sim 93$ \\
\hline BHS & 11 & 45.77 & 3.91 & 54.09 & 40.64 & 13.45 & $70 \sim 93$ \\
\hline BRA & 14 & 57.84 & 2.82 & 61.94 & 53.00 & 8.94 & $60 \sim 89$ \\
\hline CAN & 23 & 31.27 & 1.64 & 32.97 & 27.41 & 5.56 & $51 \sim 91$ \\
\hline CHL & 5 & 51.84 & 5.15 & 57.88 & 45.64 & 12.24 & $68 \sim 94$ \\
\hline $\mathrm{CHN}$ & 12 & 32.68 & 3.62 & 37.80 & 25.70 & 12.10 & $80 \sim 92$ \\
\hline COL & 7 & 51.51 & 2.48 & 54.50 & 46.00 & 8.50 & $70 \sim 91$ \\
\hline CRI & 9 & 46.00 & 2.80 & 50.00 & 42.00 & 8.00 & $61 \sim 89$ \\
\hline CSK & 12 & 22.25 & 2.29 & 27.19 & 19.37 & 7.82 & $58 \sim 92$ \\
\hline DEU & 7 & 31.22 & 1.58 & 33.57 & 28.13 & 5.44 & $63 \sim 84$ \\
\hline DNK & 4 & 32.08 & 1.09 & 33.20 & 30.99 & 2.21 & $76 \sim 92$ \\
\hline DOM & 4 & 46.94 & 2.90 & 50.46 & 43.29 & 7.17 & $76 \sim 92$ \\
\hline ESP & 8 & 32.85 & 1.73 & 37.11 & 31.02 & 6.09 & $65 \sim 89$ \\
\hline FIN & 12 & 29.93 & 2.08 & 32.04 & 26.11 & 5.93 & $66 \sim 91$ \\
\hline FRA & 7 & 43.11 & 5.62 & 49.00 & 34.85 & 14.15 & $56 \sim 84$ \\
\hline GBR & 31 & 25.98 & 2.56 & 32.40 & 22.90 & 9.50 & $61 \sim 91$ \\
\hline HKG & 7 & 41.58 & 2.60 & 45.18 & 37.30 & 7.88 & $71 \sim 91$ \\
\hline HND & 7 & 54.49 & 3.36 & 61.88 & 50.00 & 11.88 & $68 \sim 93$ \\
\hline HUN & 9 & 24.65 & 3.36 & 32.24 & 20.97 & 11.27 & $62 \sim 93$ \\
\hline IDN & 11 & 40.09 & 2.07 & 45.19 & 37.30 & 7.89 & $64 \sim 93$ \\
\hline IND & 31 & 39.15 & 2.03 & 43.65 & 35.77 & 7.88 & $51 \sim 92$ \\
\hline IRN & 5 & 49.83 & 1.26 & 52.05 & 48.48 & 3.57 & $69 \sim 84$ \\
\hline ITA & 15 & 34.93 & 2.52 & 41.00 & 32.02 & 8.98 & $74 \sim 91$ \\
\hline JAM & 9 & 48.77 & 2.84 & 54.31 & 44.52 & 9.79 & $58 \sim 93$ \\
\hline JPN & 23 & 34.82 & 1.32 & 37.60 & 32.50 & 5.10 & $62 \sim 90$ \\
\hline KOR & 14 & 34.19 & 2.54 & 39.10 & 29.82 & 9.28 & $53 \sim 88$ \\
\hline LKA & 9 & 42.45 & 4.52 & 47.80 & 35.30 & 12.50 & $53 \sim 90$ \\
\hline MEX & 9 & 54.59 & 2.76 & 57.90 & 50.00 & 7.90 & $50 \sim 92$ \\
\hline MYS & 6 & 50.36 & 1.79 & 53.00 & 48.00 & 5.00 & $70 \sim 89$ \\
\hline NLD & 12 & 28.59 & 0.91 & 29.68 & 26.66 & 3.02 & $75 \sim 91$ \\
\hline NOR & 9 & 34.21 & 2.73 & 37.52 & 30.57 & 6.95 & $62 \sim 91$ \\
\hline NZL & 12 & 34.36 & 2.78 & 40.21 & 30.04 & 10.17 & $73 \sim 90$ \\
\hline PAK & 9 & 38.10 & 0.81 & 39.04 & 36.51 & 2.53 & $69 \sim 91$ \\
\hline PAN & 4 & 52.42 & 4.34 & 57.00 & 47.47 & 9.53 & $70 \sim 89$ \\
\hline PHL & 7 & 47.62 & 2.27 & 51.32 & 45.00 & 6.32 & $57 \sim 91$ \\
\hline POL & 17 & 25.69 & 2.44 & 33.06 & 20.88 & 12.18 & $76 \sim 93$ \\
\hline PRT & 4 & 36.60 & 0.59 & 37.23 & 35.63 & 1.60 & $73 \sim 91$ \\
\hline SGP & 6 & 40.12 & 1.65 & 42.00 & 37.00 & 5.00 & $73 \sim 89$ \\
\hline SWE & 14 & 31.74 & 1.42 & 33.41 & 27.31 & 6.10 & $67 \sim 92$ \\
\hline THA & 8 & 45.48 & 3.54 & 51.50 & 41.28 & 10.22 & $62 \sim 92$ \\
\hline ТTO & 4 & 46.21 & 3.28 & 51.00 & 41.72 & 9.28 & $58 \sim 81$ \\
\hline TUN & 5 & 49.11 & 1.26 & 50.60 & 46.84 & 3.76 & $65 \sim 90$ \\
\hline TWN & 26 & 29.62 & 1.50 & 33.60 & 27.70 & 5.90 & $64 \sim 93$ \\
\hline USA & 45 & 35.28 & 1.27 & 38.16 & 33.50 & 4.66 & $47 \sim 91$ \\
\hline VEN & 9 & 44.42 & 4.02 & 53.84 & 39.42 & 14.42 & $71 \sim 90$ \\
\hline YUG & 10 & 32.62 & 0.95 & 34.73 & 31.18 & 3.55 & $63 \sim 90$ \\
\hline Overall & 573 & 36.23 & 9.15 & 61.94 & 17.83 & 44.11 & $47 \sim 94$ \\
\hline
\end{tabular}

Note: Nob - Number of observations.

(C) Royal Economic Society 1998

Copyright @ 1998 . All rights reserved. 
Table 3

Analysis of Variance of Gini Coefficients

\begin{tabular}{clrrllrrrr}
\hline \hline $\begin{array}{c}\text { Data set } \\
\text { (Nob) }\end{array}$ & Source & DF & $\begin{array}{c}\text { Sum of } \\
\text { Squares }\end{array}$ & F-Value & Source & DF & $\begin{array}{c}\text { Sum of } \\
\text { Squares }\end{array}$ & F-Value & $\begin{array}{r}\text { \% of } \\
\text { Total }\end{array}$ \\
1 & Model & 98 & $42,837.71$ & 64.84 & Country & 48 & $42,262.78$ & 130.61 & 91.81 \\
$(573)$ & Error & 474 & $3,195.24$ & & Time & 47 & 389.10 & 1.23 & 0.85 \\
& Total & 572 & $46,032.95$ & & Income & 1 & 157.00 & 23.29 & 0.34 \\
& & & & & Hhld. & 1 & 27.91 & 4.14 & 0.06 \\
& & & & & Gross & 1 & 0.93 & 0.14 & 0.00 \\
2 & Model & 98 & $44,716.93$ & 67.69 & Country & 48 & $44,280.97$ & 136.85 & 92.42 \\
$(573)$ & Error & 474 & $3,195.24$ & & Time & 47 & 389.22 & 1.23 & 0.81 \\
& Total & 572 & $47,912.17$ & & Income & 1 & 17.90 & 2.66 & 0.04 \\
& & & & & Hhld. & 1 & 27.91 & 4.14 & 0.06 \\
& & & & & Gross & 1 & 0.93 & 0.14 & 0.00 \\
3 & Model & 68 & $6,627.54$ & 17.52 & Country & 19 & $6,449.03$ & 61.00 & 82.49 \\
$(283)$ & Error & 214 & $1,190.81$ & & Time & 46 & 149.67 & 0.58 & 1.91 \\
& Total & 282 & $7,818.35$ & & Income & 1 & 19.98 & 3.59 & 0.26 \\
& & & & & Hhld. & 1 & 2.99 & 0.54 & 0.04 \\
& & & & & Gross & 1 & 5.88 & 1.06 & 0.08 \\
4 & Model & 75 & $33,320.84$ & 55.98 & Country & 28 & $32,618.22$ & 146.80 & 93.14 \\
$(290)$ & Error & 214 & $1,698.23$ & & Time & 44 & 492.43 & 1.41 & 1.41 \\
& Total & 289 & $35,019.07$ & & Income & 1 & 164.73 & 20.76 & 0.47 \\
& & & & & Hhld. & 1 & 34.14 & 4.30 & 0.10 \\
& & & & & Gross & 1 & 11.32 & 1.43 & 0.03 \\
\hline \hline
\end{tabular}

Notes. 1: DF - Degrees of freedom

2: Descriptions for different data sets:

Data set 1: The whole sample, including all definitions.

Data set 2: The whole sample, adjusted for difference in income or expenditure definitions.

Data set 3: Subsample, high-income countries, including all definitions.

Data set 4: Subsample, low- and middle-income countries, including all definitions.

concerning the two propositions. Because we have seen that standard deviation of within-country Gini coefficients is small and because a plot of the Gini coefficients by country revealed trends for some countries, we consider a simple linear trend model:

$$
g_{i t}=\phi_{i} D_{i}+\theta_{i} t_{i}+\delta_{1} d_{1}+\delta_{2} d_{2}+\delta_{3} d_{3}+\omega_{i t}
$$

where $g_{i t}$ is the Gini coefficient, $i=1,2, \ldots, N$ (number of countries), $D_{i}=1$ for country $i$ and 0 otherwise, $t_{i}=1,2, \ldots, T_{i}$, and $\omega_{i t} \sim \operatorname{iid}\left(0, \sigma_{\omega}^{2}\right)$. The panel data are unbalanced since in general $T_{i} \neq T_{j}$ for $i \neq j$. In light of the ANOVA results, we use the adjusted data but include definitional dummies to test for any remaining effect. $d_{1}$ is the control dummy for income $(=1)$ /expenditure $(=0) ; d_{2}$ is the control dummy for households $(=1) /$ individual $(=0) ; d_{3}$ is the control dummy for gross income $(=1) /$ net income $(=0)$.

We would like to know whether, after controlling for the differences in definitions, the difference between the country specific effects $\phi_{1}, \phi_{2}, \ldots$, and $\phi_{N}$ is statistically significant or not and we want to test for the existence of a (C) Royal Economic Society 1998 
significant, within-country time trend, $\theta_{1}, \theta_{2}, \ldots, \theta_{N}$. Accordingly, we test the following two hypotheses:

(a) $\mathrm{H}_{0}^{a}: \phi_{1}=\phi_{2}=\ldots=\phi_{N}$,

(b) $\mathrm{H}_{0}^{b}: \theta_{i}=0$, for $i=1,2, \ldots, N$.

Based on the F-statistic in Table 4, hypothesis (a) is rejected at a $5 \%$ significance level. This confirms our first proposition - Gini coefficients differ significantly across countries. For individual time trends, we find statistical support for our second proposition in 32 of the 49 countries or $65 \%$ of the

Table 4

LSDV Estimation Results (Unrestricted Regression)

Dep var.: GINI

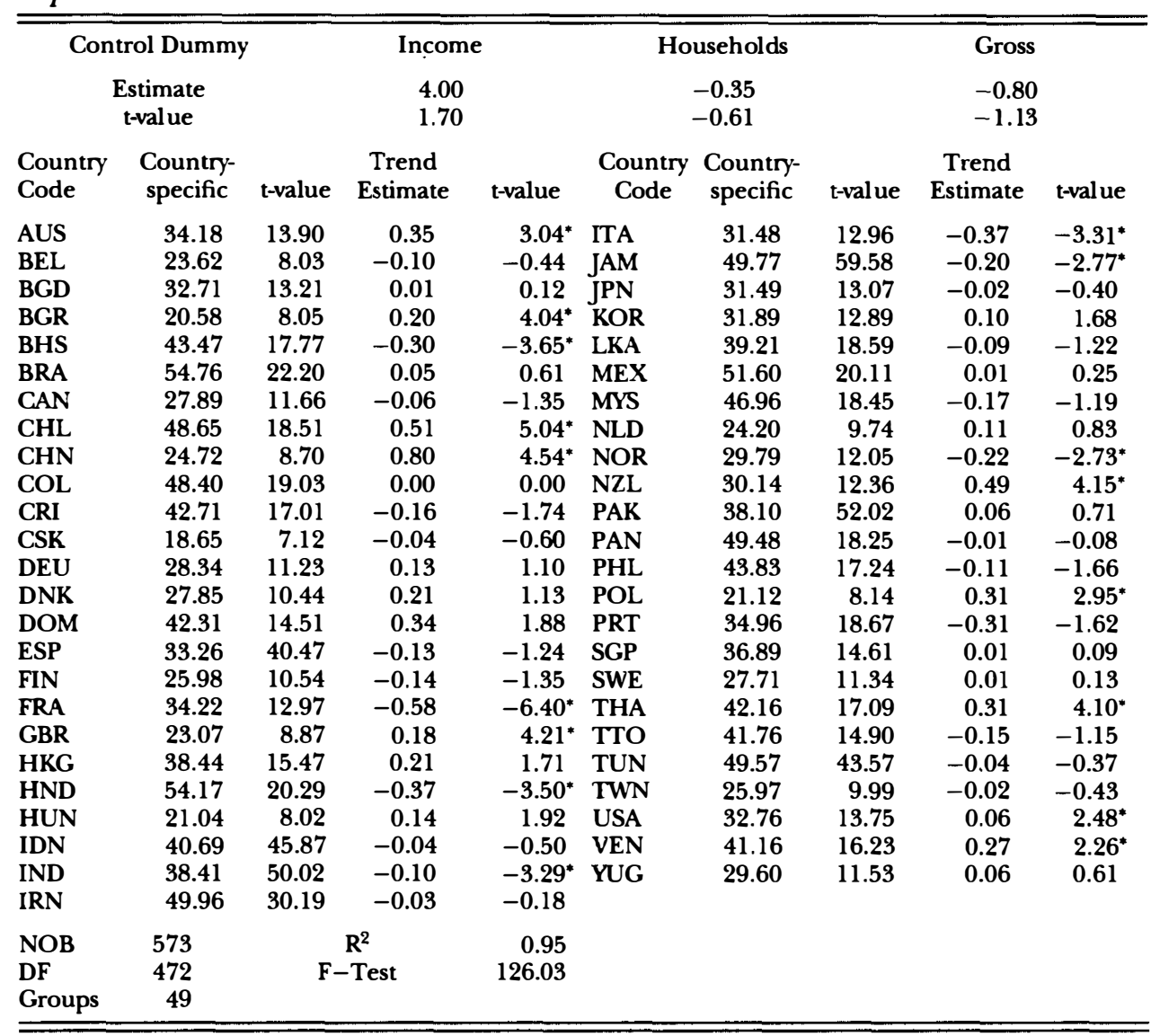

Notes. 1. Standard errors of individual country specific effects: 9.89 .

2. For hypothesis (a), the F-statistic is 126.03 . This leads to the rejection of hypothesis (a).

3. For hypothesis (b), 7 countries have significant negative trend, 10 countries have significant positive trend. (There is a total of 17 countries with significant trends (indicated by $\left(^{*}\right)$.)

4. The country-specific terms are equivalent to the 1980 predicted Gini coefficients.

(C) Royal Economic Society 1998 
sample. ${ }^{5}$ For 7 countries, however, we find significant negative trends, while 10 countries have significant positive trends when we apply the $5 \%$ t-test. But of the 17 countries with a significant trend, 10 of them have time trends that are quantitatively small - defined here as an annual change of less than $1.0 \%$ of the country's 1980 predicted Gini coefficient, the estimated country-specific term in the regression reported in Table 4 . This is, of course, an arbitrary cutoff point. We note, however, that applying the mean absolute rate of change $(0.6 \%$ a year) for these 10 countries to the average Gini coefficient (36.2) for our entire sample, it would take more than 20 years for the index to move 5 points. This compares with a difference between the maximum and minimum 1980 predicted values for each country of 36.1 points. Thus, whether or not one considers movements of $0.6 \%$ a year quantitatively large, it is clear that intertemporal changes are very modest compared with international differences.

For seven countries (Australia, Chile, China, France, Italy, New Zealand, and Poland), however, we observe a statistically large and quantitatively important time trend, thus establishing that countries can change the degree of inequality as measured by the Gini coefficient relatively quickly. For example, the results for New Zealand indicate an annual change of $1.6 \%$ implying that a change of 5 points in the Gini index could be achieved in only 10 years. The factors affecting changes of this magnitude in these 'non-conforming' countries present an interesting opportunity for future research. Here we simply note that four of the countries - Australia, France, Italy, and New Zealand are OECD countries where the fiscal system in general and the welfare system in particular are well developed so that, given the political will, it should be feasible to influence inequality. And in the remaining countries, China and Poland have of course been experiencing major structural changes during the period covered by our sample.

Because we have less than 10 observations for 28 countries, the test for a significant trend may not be accurate. Reducing the sample to only those countries with 10 or more observations, however, yields broadly similar results. For the 21 countries with at least 10 observations, the time trend is insignificant for 12 countries, and in the 9 countries where the time trend is significant it is quantitatively important (an annual change of more than $1 \%$ of the mean) in only four countries - China, Italy, New Zealand, and Poland. For the group of 21 countries, the average absolute trend is 0.16 , or an average absolute percentage change of $0.52 \%$ per year. For the 7 countries with at least 20 observations, the results are even stronger. Three countries have an insignificant time trend, and of the other 4 none have a quantitatively important trend.

\footnotetext{
5 Since most of the countries do not have enough observations to allow for suitable unit root tests, we have not pursued this approach. For the United States and United Kingdom, there are observable positive time trends since late 1970's and early 1980's. Since 1970, inequality in the United States has increased at a rate of $0.62 \%$ a year, while in the United Kingdom, the increase has been $1.37 \%$ a year. For the US data which have the longest time series, the simple Augmented Dickey-Fuller test suggests the presence of a unit root. However, in Raj and Slottje (1994), they found that the US Gini is stationary around a broken trend.
}

(C) Royal Economic Society 1998 
In fact, the average absolute trend for this group is only 0.1 , while the average absolute percentage change is only $0.32 \%$ per year. Thus, for the countries where we have the most complete and reliable data, inequality appears to be quite stable over relatively long periods of time.

Recall that the results reported in Table 4 use the adjusted data for the Gini coefficient. With these data, we see that the definitional dummies are not significant. We also obtain broadly similar results for our two propositions (not reported) for the unadjusted data and in the subsample of observations with the same definition.

We have also estimated a random-effects model (with or without a time trend and using the adjusted data) to account for the loss of degrees of freedom in the LSDV regression. We assume that the country-specific effects are drawn from a random distribution, while at the same time controlling for the definition differences. The results are presented in Table 5. The only significant explanatory variable is the constant term with an estimated value of 37.7, close to the sample average. As a result of the large variation in Gini coefficients across countries, the constant has a standard error between 9.71 (without the time trend) and 9.82 (with the time trend) that is very close to the standard error of the country-specific effects (9.89) in the LSDV regression. Thus, the constant term in the random-effects model plays the same role as the country-specific terms in the LSDV regression, lending support to our assertion that the variations in inequality arise mainly from cross-country differences. Note also that the random-effects model provides no support for a general time trend: the mean value of the time trend is not significant with a $95 \%$ confidence interval of $(-0.015,0.035)$.

Taken together, these results provide substantial support for our two propositions. Thus, Gini coefficients are clearly different across countries (propo-

Table 5

Random-effects Regression of Gini Coefficients

Dep var.: GINI

\begin{tabular}{|c|c|c|c|c|}
\hline & \multicolumn{2}{|c|}{ Model I } & \multicolumn{2}{|c|}{ Model II } \\
\hline & Estimate & t-value & Estimate & t-value \\
\hline Constant & 37.67 & 17.31 & 37.74 & 17.23 \\
\hline Income & 1.07 & 0.57 & 1.03 & 0.55 \\
\hline Households & -0.43 & -0.84 & -0.52 & -1.00 \\
\hline Gross & 0.77 & 1.20 & 0.78 & 1.21 \\
\hline Trend & & & 0.01 & 0.80 \\
\hline Nob & 573 & & 573 & \\
\hline DF & 569 & & 568 & \\
\hline Groups & 49 & & 49 & \\
\hline
\end{tabular}

Notes: Standard errors of error terms: Individual constant terms: 9.71 (Model I), 9.82 (Model II).

Standard errors of error terms: White noise error: 2.63 (Model I), 2.63 (Model II).

(C) Royal Economic Society 1998 